\title{
Consideraçōes sobre os ventos na Região Amazônica
}

\author{
José Marques (') \\ Jesus Marden dos Santos $\left({ }^{2}\right)$ \\ Eneas Salati $\left({ }^{3}\right)$
}

Os estudos da direção e da velocidade do vento em diferentes altitudes representa, além de segurança, economia e conforto de viagens aêreas, um conhecimento útil para inumeráveis aplicações. A direção e a velocidade predominantes do vento sobre uma região desempenha um papel importante na estimativa de trajetórias de poluentes lançados à atmosfera bem como no dimensionamento das torres e das linhas aéreas de transmissão de energia elétrica.

Tendo em vista as possibilidades futuras de instalação de indústrias na região amazônica, especialmente nas proximidades de Belém e Manaus, julgamos oportuna a divulgação de resultados obtidos em estudos realizados naquela região para o ano de 1972 .

Tendo como fonte os dados meteorológicos de superfície (temperatura, vento, umidade e precipitação) e de altitude (vento, temperatura e umidade) estudos hidrometeorológicos tem sido realizados sobre a região amazônica, Marques (197b) e Marques et al. (1977), ficandn caracterizada a distribuição vertical dos ventos, desde próximo à superfície até o nivei aproximado de 5500 metros. O vento horizontal foi decomposto nas suas componentes (u) e (v), segundo a convenção universalmente adotada.

Foram estudados os ventos em altitude sobre Belém e Manaus, a partir de informações de 364 e 294 sondagens aerológicas, respectivamente, perfazendo um total de 658 sonaagens, as quais foram realizadas diariamente às 12:00 horas TCG (9:00 local) pelo Serviço de Meteorologia do Ministério da Aeronáutica em estações sinóticas de altitude situadas na região.

Os níveis isobáricos padrões estudados bem como suas respectivas altitudes encontradas foram os seguintes:

\footnotetext{
(1) - Departamento de Meteorologia - Instituto de Geociências - UFRJ.

(2) - Departamento de Física e Meteorologia - ESALO/USP

(3) - Centro de Energia Nuclear na Agricultura - CENA/ESALQ/USP.
} 


\begin{tabular}{cc}
\hline $\begin{array}{c}\text { Nivel isobárico } \\
\text { padrão (em mb) }\end{array}$ & $\begin{array}{c}\text { Altitude média } \\
(\mathrm{m})\end{array}$ \\
\hline & \\
1000 & 100 \\
850 & 1520 \\
700 & 3150 \\
500 & 5860 \\
\hline
\end{tabular}

Para cada mês e em cada nível foram lançados os valores de $u$, (ou v), e traçaram-se as respectivas isolinhas para obtenção dos campos do vento representados pelas figuras 1 a 4 .

As figuras 1 e 2 apresentam a variação mensal e em altitude da componente zonal (u) do vento, a qual é convencionalmente tomada

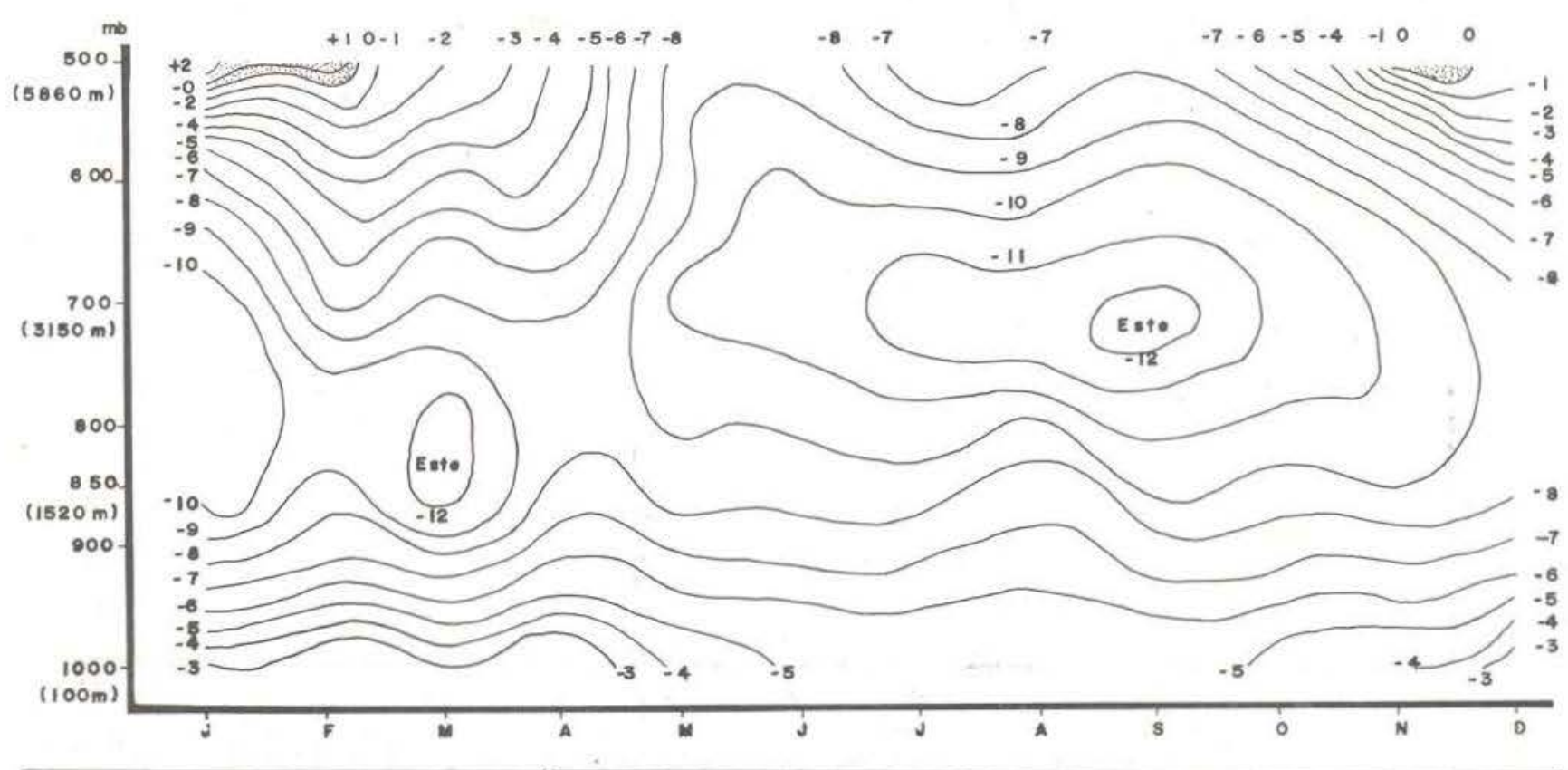

Figura 1 - Variação mensal e por camada, da componente zonal (u) do vento em Belém. Isolinhas em $\mathrm{m} / \mathrm{s}$.

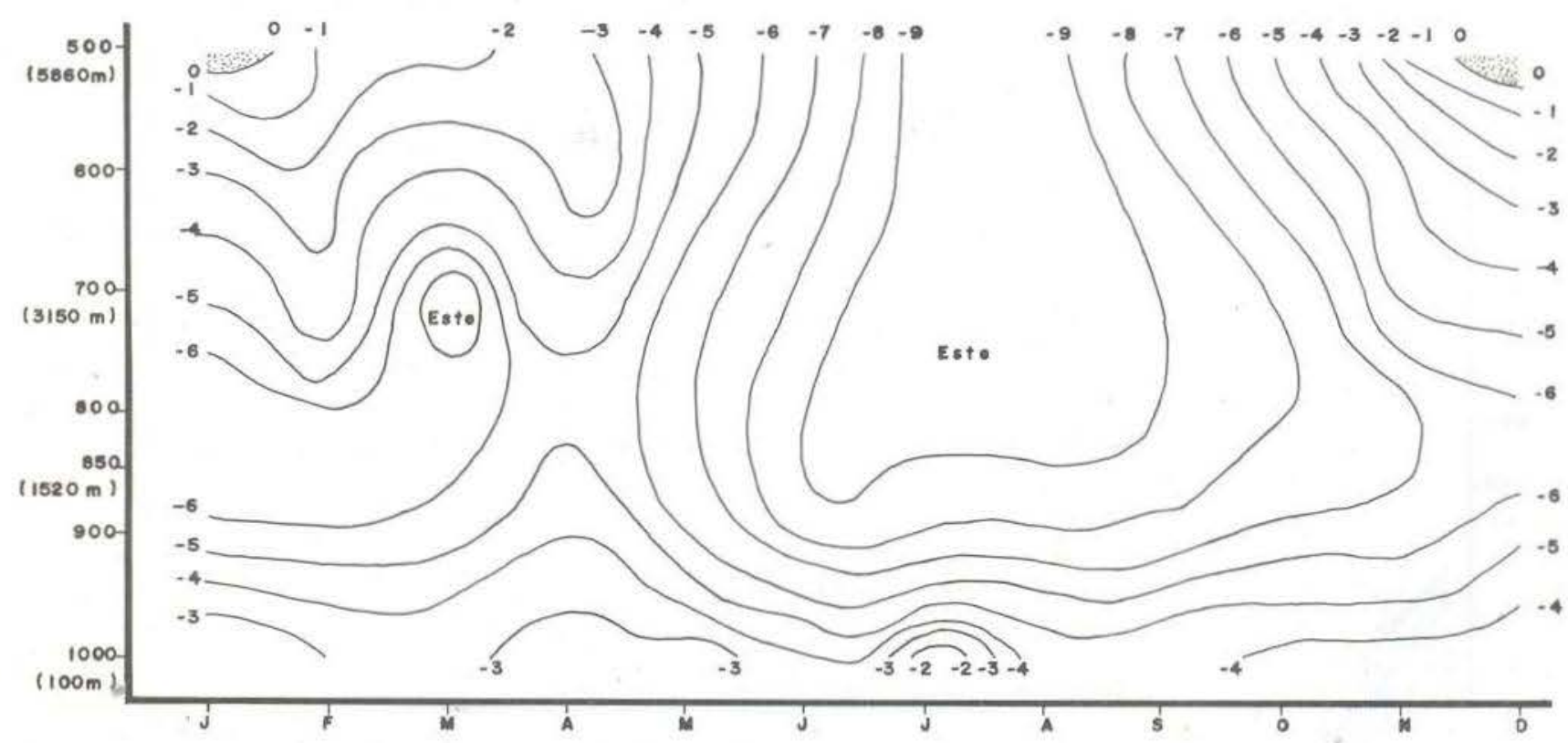

Figura 2 - Variação mensal e por camada da componente zonal (u) do vento em Manaus. Isolinhas em $\mathrm{m} / \mathrm{s}$. 
como paralela aos círculos terrestres e sendo do sentido positivo aquele de Oeste para Leste.

Verificou-se que a componente zonal, tanto em Manaus como em Belém, foi no sentido de Leste para Oeste durante todo o ano e em todos os níveis estudados e que os valores máximos encontram-se próximos aos $1500 \mathrm{me}$ tros em ambas as localidades. Sobre Belém estes máximos foram superiores aos verificados para Manaus, devido ao atrito com a superfície florestada. Notou-se que os valores máximos ocorreram em março e setembro.

Próximo à superfície e durante o ano, os valores situaram-se em torno de $4 \mathrm{~m} / \mathrm{s}$.

A componente do vento na direção meridional (v) apresentou, em Belém, até os 600

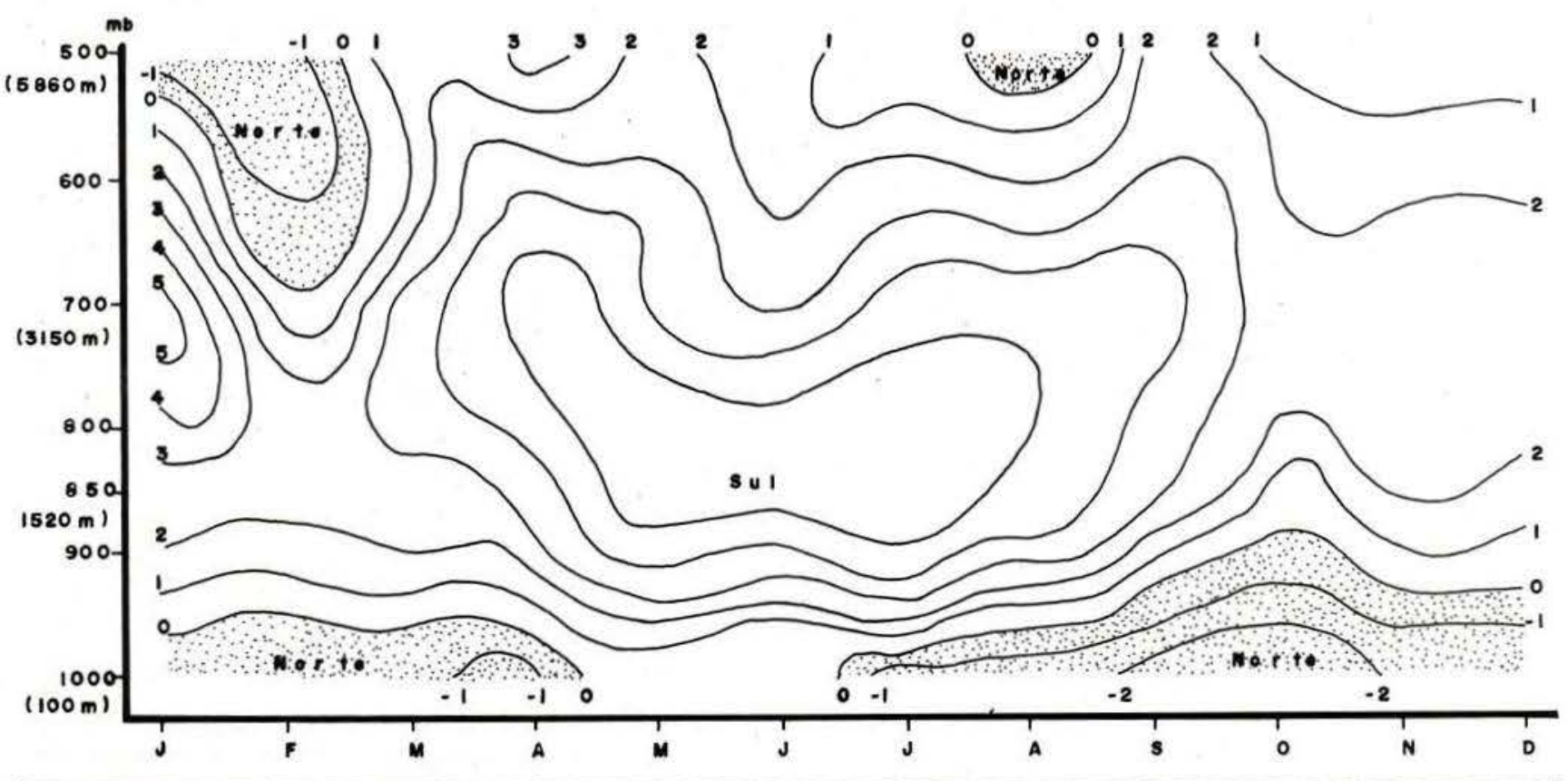

Figura 3 - Variação mensal e por camada isobárica da componente meridional ( $v$ ) do vento em Belém. Isolinhas $\mathrm{em} \mathrm{m} / \mathrm{s}$.

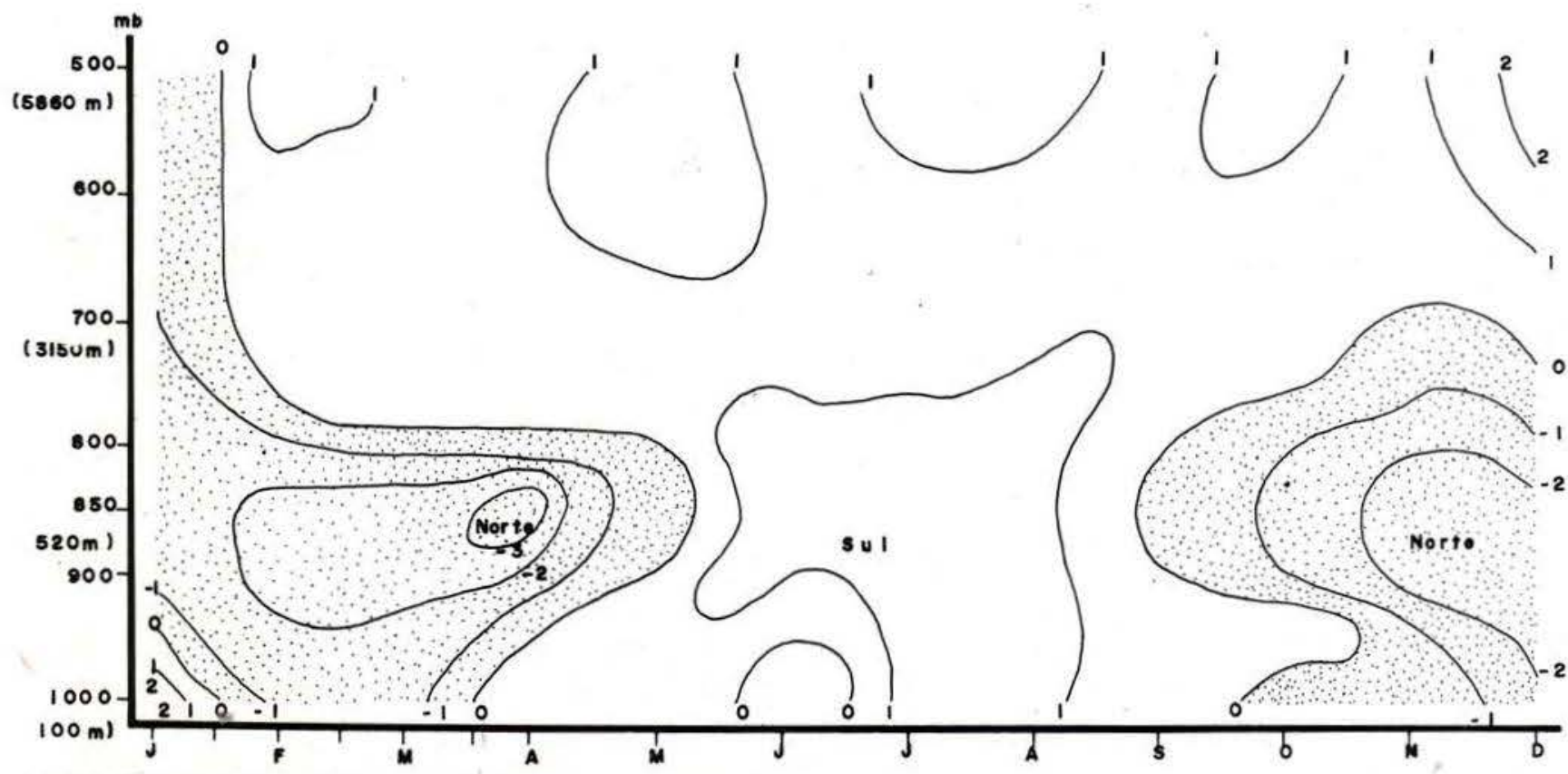

Figura 4 - Variação mensal e por camada da componente meridional (v) do vento em Manaus. Isolinhas em $\mathrm{m} / \mathrm{s}$. 
metros aproximadamente, sentido de Norte para Sul de janeiro a abril e de julho a dezembro (Fig. 3).

Entre os 3150 e os 5860 metros, em janeiro e fevereiro, o sentido também foi de Norte para Sul. Nos demais niveis e meses o sentido foi de Sul para Norte.

Em Manaus (Fig. 4), o sentido Norte-Sul predominou de janeiro a março e de outubro a dezembro, desde próximo a superfície até os 3150 metros, sendo que em janeiro e fevereiro, esta dominância estabeleceu-se até os 5500 metros.

Notou-se que, para as localidades estudadas, os valores da componente zonal foram superiores aos da componente meridional e que em Belém eles foram superiores aos de $\mathrm{Ma}$ naus, evidenciando a predominância da circulação latitudinal na área.

\section{SUMMARY}

The winds above Belém and Manaus were studied from the data of 658 daily meteorological upper air observations (radiosonde) at 12:00 TCG (9:000 local time), by the "Serviço de Meteorologia do Ministério da Aeronáutica".

The standard isobarias studied were $1000,850,700$ and $500 \mathrm{mb}$.

It was observed that the zonal components were greater than the meridional component. Also those from Belém were greater than those from Manaus, showing the predominance of East-West circulation.

\section{BIBLIOGRAFIA CITADA}

MARQues, $J$.

1976 - "Contribuiçăo ao estudo hidrológico da bacia amazônica". Tese de Mestrado, ESALQ, Piracicaba, São Paulo.

Marques, J.; Santos, J. M.; Villa Nova, N. A. \& Salatt, E.

1977 - Precipitable water and water vapor flux between Belém and Manaus. Acta Amazonica, Manaus, 7 (3).

(Aceito para publicação em 10/11/77) 